Braz J Med Biol Res, October 2011, Volume 44(10) 973-991

doi: 10.1590/S0100-879X2011007500111

\section{Drugs and lifestyle for the treatment and prevention of coronary artery disease - comparative analysis of the scientific basis}

P.L. da Luz, M. Nishiyama and A.C.P. Chagas

The Brazilian Journal of Medical and Biological Research is partially financed by

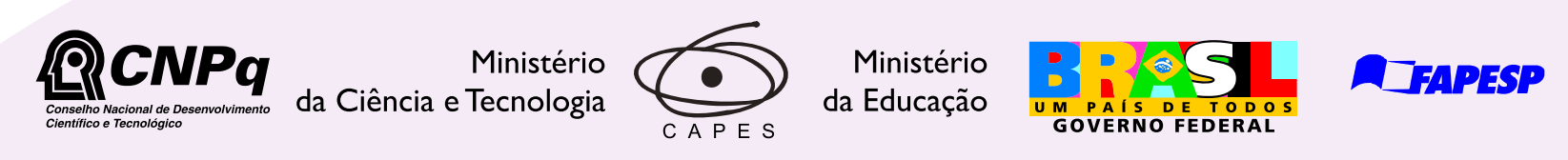

Institutional Sponsors
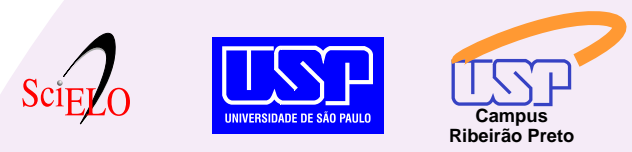

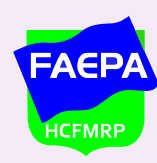

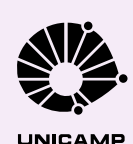

UNICAMP
Ф SHIMADZU

Explore High - Performance MS Orbitrap Technology In Proteomics \& Metabolomics

analitica Thermo 


\title{
Drugs and lifestyle for the treatment and prevention of coronary artery disease - comparative analysis of the scientific basis
}

\author{
P.L. da Luz, M. Nishiyama and A.C.P. Chagas \\ Instituto do Coração, Faculdade de Medicina, Universidade de São Paulo, São Paulo, SP, Brasil
}

\begin{abstract}
In this article, we compare two strategies for atherosclerosis treatment: drugs and healthy lifestyle. Statins are the principal drugs used for the treatment of atherosclerosis. Several secondary prevention studies have demonstrated that statins can significantly reduce cardiovascular events including coronary death, the need for surgical revascularization, stroke, total mortality, as well as fatal and non-fatal myocardial infarction. These results were observed in both men and women, the elderly, smokers and non-smokers, diabetics and hypertensives. Primary prevention studies yielded similar results, although total mortality was not affected. Statins also induce atheroma regression and do not cause cancer. However, many unresolved issues remain, such as partial risk reduction, costs, several potential side effects, and long-term use by young patients. Statins act mainly as lipid-lowering drugs but pleiotropic actions are also present. Healthy lifestyle, on the other hand, is effective and inexpensive and has no harmful effects. Five items are associated with lower cardiac risk: non-smoking, BMI $\leq 25$, regular exercise (30 min/ day), healthy diet (fruits, vegetables, low-saturated fat, and 5-30 g alcohol/day). Nevertheless, there are difficulties in implementing these measures both at the individual and population levels. Changes in behavior require multidisciplinary care, including medical, nutritional, and psychological counseling. Participation of the entire society is required for such implementation, i.e., universities, schools, media, government, and medical societies. Although these efforts represent a major challenge, such a task must be faced in order to halt the atherosclerosis epidemic that threatens the world.
\end{abstract}

Key words: Atherosclerosis; Statins; Lifestyle; Coronary disease; Prevention

\section{Introduction}

Cardiovascular disease (CVD) is the main cause of death in Brazil, as well as in the world, including rich and poor countries. One century ago, CVD accounted for less than $10 \%$ of all deaths worldwide, while today it is responsible for approximately $30 \%$, including nearly $40 \%$ of deaths in high income countries and about $28 \%$ in countries with low or average income (1).

In Brazil, mortality from CVD is estimated to be $33 \%$ (2). Of note is the increase in the number of elderly individuals, especially over 80 years of age. Such group accounted for $0.32 \%$ of the general population in the USA in 1950 , as opposed to $0.74 \%$ in 1990 (an increase of over $130 \%$ ). In Brazil, this group represented $0.4 \%$ of the general population in 1980 and $0.9 \%$ in 2001. Furthermore, in 2000, approximately $15 \%$ of the population was 50 years of age or older. This percentage is expected to reach $42 \%$ by 2050 . As the Brazilian population gets older, non-communicable diseases will burden the health care system, and the costs associated with such diseases already account for half the costs of all hospital admissions. Non-communicable diseases account for $66 \%$ of all diseases, while contagious diseases account for $24 \%$ and injuries for $10 \%$ (2). This rate of non-communicable diseases is not necessarily an inevitable result of modern society, but rather a problem that can be avoided. The main factors behind most of these diseases, i.e., coronary artery disease (CAD), stroke, diabetes, and several types of cancer, are not genetic but rather environmental and behavioral. Atherosclerosis in particular is responsible for most cardiovascular events.

Atherosclerosis is a chronic inflammatory and prolifera-

Correspondence: P.L. da Luz, Instituto do Coração, Faculdade de Medicina, Universidade de São Paulo, Av. Dr. Enéas C. Aguiar, 44, 5o andar, Sala 8, 05403-000 São Paulo, SP, Brasil. E-mail: daluzp@incor.usp.br

Received March 11, 2011. Accepted August 10, 2011. Available online August 26, 2011. Published October $10,2011$. 
tive disease, which may cause obstructions of the coronary, cerebral and peripheral arteries. Atherosclerosis tends to be a progressive process that begins early in life, probably in childhood. It is typically multifactorial in origin, most often dependent on risk factors such as hypercholesterolemia, diabetes, smoking, hypertension, sedentarism, and obesity. Atherosclerosis results from a complex interaction of hemodynamic and biochemical factors and is determined by circulating blood cells, endothelial cells, smooth muscle cells, blood lipids, and connective tissue of the arterial wall. Once considered to be the result of fat deposition in the arterial wall, it is now viewed as an inflammatory and proliferative process that can lead to arterial wall thickening and eventual complete obstruction that hampers myocardial blood flow, thus causing the clinical syndromes of angina or infarction (3). These mechanisms, however, are not the subject of this paper.

As far as clinical evolution is concerned, coronary atherosclerosis has two distinct phases (Figure 1): the asymptomatic phase that may begin at birth and proceed until mid-life when symptoms occur. This phase is usually associated with non-obstructive lesions. However, some of these lesions may suffer acute instabilization due to plaque rupture, with partial or total occlusions, causing acute coronary syndromes or infarction.

The symptomatic phase is characterized by flow limiting, advanced lesions and is associated with classical clinical manifestations such as effort angina, heart failure or myocardial infarction (MI). Hence, this is the phase that more commonly causes complications.

Until recently, most medical efforts were directed towards the symptomatic phase, including diagnostic procedures and treatments. Lately, more emphasis has been placed on identifying patients in the early, asymptomatic phase. Thus, several biomarkers and noninvasive imaging techniques have been developed whose main goal is to identify individuals in the early stages of atherosclerosis, in order to avoid its progression or even to prevent its development.

CAD is responsible for most clinical complications of atherosclerosis. Its treatment is basically covered by four types of interventions: 1) coronary surgery; 2) percutaneous coronary interventions; 3) drug treatment; 4) lifestyle modification.
The first two focus on CAD complications, such as angina or infarction, do not interfere with the biochemical nature of the disease. Drugs and healthy lifestyle, on the other hand, not only can prevent disease development but can also prevent complications, reduce or abolish progression and even induce plaque regression.

The choice of either approach or of a combination of the two has major implications, including effectiveness, costs, adherence, and side effects. The purpose of this article is to compare these two latter approaches, drug treatment and lifestyle modification, highlighting the peculiarities of each one and offering practical suggestions for physicians.

\section{Drugs}

Ancel Keys, in his landmark Seven Countries Study published in 1966 (4), observed that cardiac mortality was directly associated with fat consumption in different countries; the more fat people ate, the greater was coronary mortality. In 1961, Kannel et al. (5) showed a direct association between plasma cholesterol and cardiac mortality in the Framingham Study, with mortality also substantially increasing with increasing blood pressure. These two fundamental clinical observations followed the original discoveries of the Russian investigators Anichkov, Ignatowski and Chalatov (6) who, in the early 1900's, fed rabbits with milk and eggs and demonstrated that atherosclerosis was produced only by egg cholesterol. Although it took about 50 years for these basic discoveries to reach the clinical

\section{HUMAN ATHEROSCLEROSIS}

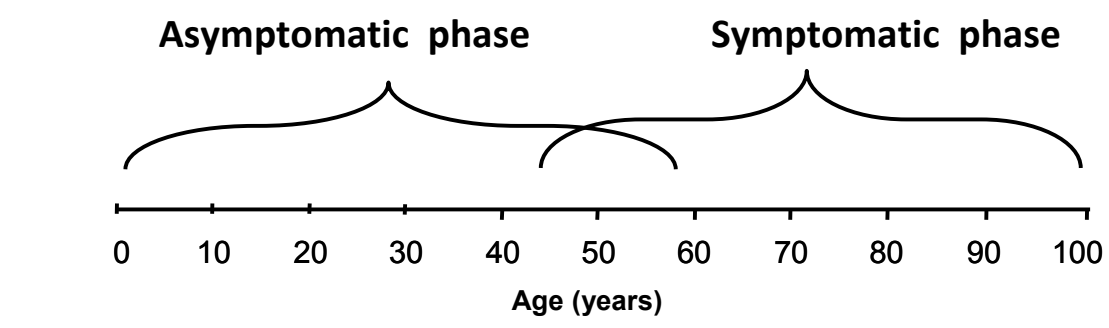

\section{- Non-obstructive lesions \\ - Risk factors \\ - Genetic predisposition \\ - Non-invasive lesion detection}

$\bullet \pm \mathbf{4 0 \%}$ CAD without Risk Factors

Figure 1. Spectrum of human atherosclerosis. Although most clinical manifestations occur at middle age, the disease actually begins at birth and has a long asymptomatic period (see text). $\mathrm{AMI}=$ acute myocardial infarction; $\mathrm{ACS}$ = acute coronary syndrome; CAD = coronary artery disease. 
arena, when they finally did, their impact was immense and changed medical research and practice forever. Several epidemiological studies subsequently confirmed these relationships, which covered a wide range of cholesterol concentrations, including those considered to be normal or mildly elevated. Both drug therapy and diets began to be tested to ascertain whether they could change the natural history of atherosclerosis. Definitive assessment of whether LDL reduction would be beneficial was facilitated by the development of potent cholesterol-lowering drugs, the 3-hydroxy-3-methylglutaryl coenzyme A (HMG-CoA) reductase inhibitors, termed statins. Since then a series of studies have demonstrated their efficacy in preventing major cardiovascular events.

\section{Secondary prevention}

Patients who had already experienced coronary events, those at particularly high risk for events, namely diabetics and patients with peripheral artery disease, were the initial natural focus. Some of the most important trials are summarized here.

In the Multiple Risk Factor Intervention Trial (MRFIT) (7), $69 \%$ of deaths from CAD in the first 6 years of followup occurred in subjects with total cholesterol (TC) between 182 and $264 \mathrm{mg} / \mathrm{dL}$. In the first 16 years of the Framingham Heart Study, $40 \%$ of participants who developed MI had TC levels between 200 and $250 \mathrm{mg} / \mathrm{dL}$.

All-cause mortality was significantly reduced, due mainly to a significant $18 \%$ decrease in coronary deaths. The authors concluded that adding simvastatin to existing treatments safely produced substantial additional benefits for a wide range of high-risk patients, irrespective of their initial cholesterol concentrations.

In the Scandinavian Simvastatin Survival Study (7) the HMG-CoA reductase inhibitor simvastatin reduced total mortality in patients with CVD by $30 \%$ mainly due to a $42 \%$ reduction in deaths from CAD. The secondary endpoint, analyzed by time of first event, was "major coronary events", which comprised coronary deaths, definite or probable hospital-verified non-fatal acute $\mathrm{MI}$, resuscitated cardiac arrest, and definite silent MI verified by electrocardiogram. Simvastatin produced highly significant reductions in the risk of death and morbidity for patients with coronary heart disease (CHD) followed for a median tie of 5.4 years. The $4 \mathrm{~S}$ study also provided evidence for a beneficial effect of simvastatin on fatal plus nonfatal cerebrovascular events.

Subsequently, in the CARE Trial (7), another statin - pravastatin, was shown to reduce fatal and nonfatal coronary events in patients with CAD. The purpose of the CARE Trial was to investigate whether the benefit achieved by lowering the LDL cholesterol levels of patients who had hypercholesterolemia could be extended to patients with CAD and average LDL. The results showed that reducing LDL cholesterol from average to low levels (from a mean of 139 to a mean of $97 \mathrm{mg} / \mathrm{dL}$ ) significantly decreased recurrent coronary events. The magnitude of the risk reduction was consistent for the major end points of myocardial infarction, i.e., coronary death, bypass surgery and angioplasty. However, there was no significant reduction in overall mortality.

In addition, the CARE Trial showed that patients 60 years old or older, women and those with impaired left ventricular ejection fraction, in all of whom the efficacy of lowering cholesterol levels had been questioned, also experienced a similar risk reduction. Stroke, a specified endpoint in the CARE Trial, was significantly reduced by $31 \%$ in the pravastatin group. This agreed with the reduction in cerebrovascular endpoints found in post hoc analyses of data from several previous trials conducted in hypercholesterolemic populations. A meta-analysis of pravastatin trials in patients with atherosclerosis showed a significant $62 \%$ reduction in stroke.

The long-term intervention with pravastatin in ischemic disease (LIPID Study) (7) was another study with pravastatin, which provided evidence that lowering cholesterol levels with statin in patients with a broad range of initial cholesterol levels and a history of MI or unstable angina reduced the risk of death from CAD, CVD, and all causes combined. In addition, the risk of MI or stroke was significantly reduced.

These results extended the findings of the 4S, which showed that treatment had benefits in terms of mortality from CHD and overall mortality among patients with CHD who had a mean cholesterol level of $261 \mathrm{mg} / \mathrm{dL}$ at study entry. In the LIPID Study, results demonstrated similar benefits in patients with a mean cholesterol level about 44 $\mathrm{mg} / \mathrm{dL}$ lower than in $4 \mathrm{~S}$.

The LIPID Study also extended the findings of the CARE Study, which had shown a reduction in the composite death outcome due to CAD and nonfatal MI in patients with CAD with a similar mean cholesterol level of $209 \mathrm{mg} / \mathrm{dL}$ at entry; mortality, also was reduced.

The heart protection study (HPS) (7), a large British study of about 20,536 patients who were cared for by their attending physicians, demonstrated more than a $20 \%$ reduction in vascular events in patients with prior MI, stroke, peripheral vascular disease, or diabetes and TC levels as low as $135 \mathrm{mg} / \mathrm{dL}$, a substantial number of whom had LDL under $100 \mathrm{mg} / \mathrm{dL}$. By implication, this result suggests that these agents may work by additional mechanisms that are unrelated to lipid lowering. Some investigators have suggested that statins also have pleiotropic properties, such as modulation of inflammation within the arterial wall, that may contribute to their beneficial effect. In the AngloScandinavian Cardiac Outcomes Trial (Ascot) (7), 19,342 subjects aged 40 to 79 years, with hypertension and at least three other cardiovascular risk factors were randomized to one of two antihypertensive regimens. The lipid-lowering arm included 10,305 subjects with TC of $6.5 \mathrm{mM}$ or less 
who were randomized to receive $10 \mathrm{mg}$ atorvastatin in addition to their anti-hypertensive treatment, or placebo. The primary endpoints were death from $\mathrm{CHD}$ and nonfatal heart attack. After 3.3 years, atorvastatin had shown clear benefits over placebo, yielding a relative risk reduction of $36 \%$. Additional benefits were reduced risk of stroke, total cardiovascular events, and total coronary events.

These and other well-conducted studies firmly established that cholesterol lowering, independently of baseline values, reduced cardiovascular events in a broad population spectrum, including those who suffered previous events and those at high risk as well.

\section{Primary prevention}

The fact that the benefit from LDL reduction in patients without clinical CAD (primary prevention) extends to individuals with average serum cholesterol levels, women, diabetics, smokers, and older persons was observed in the Air Force/Texas Coronary Atherosclerosis Prevention Study (AFCAPS/TexCAPS) (8). A cohort of healthy middle-aged and older men and women with average TC and LDL levels and with below-average HDL-C levels was studied.

The primary endpoint was the incidence of first acute major coronary events, fatal or nonfatal acute MI (AMI), unstable angina, or sudden cardiac death. Treatment with lovastatin resulted in a $37 \%$ reduction in the risk for first acute major coronary events, defined as fatal or nonfatal AMI, unstable angina or sudden cardiac death. The differences between the two treatment groups appeared as early as after one year. Analysis of secondary endpoints confirmed that the composite primary endpoint was representative of its components: lovastatin therapy significantly reduced the risk for fatal or nonfatal AMI by $40 \%$ and the risk for unstable angina by $32 \%$. Risk reduction with lovastatin across the spectrum of cardiovascular events was further confirmed by a $33 \%$ risk reduction in the need for revascularizations and $25 \%$ risk reductions in both total cardiovascular and total coronary events.

The West of Scotland Coronary Prevention Study (WOSCOPS) (8) was a double-blind study designed to determine whether the administration of pravastatin to men with hypercholesterolemia and no history of $\mathrm{Ml}$ reduced the combined incidence of nonfatal AMI and death from CAD. A total of 6595 subjects underwent randomization. Pravastatin lowered plasma TC levels by $20 \%$, LDL by $26 \%$, and triglycerides (TG) by $12 \%$, whereas HDL was increased by $5 \%$. There were no such changes with placebo. Reductions in all-cause and CAD mortality were not significant; noncardiovascular death, including death from cancer, trauma or suicide, did not differ between groups. Compared to placebo, statin treatment reduced the risk of fatal or nonfatal coronary events by approximately $30 \%$. These two major trials lend support to the concept that hypercholesterolemia alone, even in the absence of overt
CAD, deserves treatment both in men and women.

\section{Acute phase}

Patients suffer the highest rate of death and recurrent ischemic events during the early period after an acute coronary syndrome (ACS), but when the Myocardial Ischemia Reduction with Aggressive Cholesterol Lowering Trial (Miracle) (7) was designed it was not clear whether early initiation of treatment with a statin could reduce the occurrence of early events. Thus, Miracle sought to determine whether treatment initiated 24 to $96 \mathrm{~h}$ after an ACS reduces death and nonfatal ischemic events. A total of 3086 adults aged 18 years or older with unstable angina or non-Q-wave AMI were stratified and randomly assigned to receive treatment with atorvastatin ( $80 \mathrm{mg} /$ day) or matching placebo after hospital admission. Atorvastatin reduced recurrent ischemic events over a 16 -week period of treatment. There was a $2.6 \%$ absolute reduction and a $16 \%$ relative reduction in the primary combined endpoint of death, nonfatal AMI, cardiac arrest with resuscitation, or worsening symptomatic myocardial ischemia with objective evidence and emergency rehospitalization. Although the study was not powered to assess mortality, it did show beneficial effects of atorvastatin on ACS.

The pravastatin or atorvastatin evaluation and infection therapy-thrombolysis in MI (Prove It-Timi Trial) (9) was designed to compare the standard degree of LDL cholesterol lowering to approximately $100 \mathrm{mg} / \mathrm{dL}$ with $40 \mathrm{mg}$ pravastatin daily with more intensive LDL cholesterol lowering to approximately $70 \mathrm{mg} / \mathrm{dL}$ with $80 \mathrm{mg}$ atorvastatin daily as a means of preventing death or major cardiovascular events in patients with ACS.

The more intensive regimen resulted in a lower risk of death from any cause or major cardiac events than did a more moderate degree of lipid lowering. Intensive therapy with atorvastatin resulted in a median LDL cholesterol level of $62 \mathrm{mg} / \mathrm{dL}$ compared with $95 \mathrm{mg} / \mathrm{dL}$ for standard-dose pravastatin. Intensive therapy had a consistent beneficial effect on cardiac events, including a significant $29 \%$ reduction in the risk of recurrent unstable angina and a $14 \%$ reduction in the need for revascularization. The reduction in the rate of death from any cause was of borderline significance $(28 \%, P=0.07)$, suggesting that more aggressive lipid lowering is important not only to reduce the risk of recurrent ischemia, but possibly also to decrease the risk of fatal events.

Reduction of clinical events with more intensive lipidlowering therapy was apparent as early as 30 days after the beginning of therapy. This reduction was similar to that reported with statin treatment in the placebo-controlled Miracle Trial. These data corroborated previous observations that patients with ACS can particularly benefit from early and intensive lipid-lowering therapy with statins. Acute LDL lowering by statins and simultaneous improvement in endothelial function have also been demonstrated. Based 
on these observations, it is now generally accepted that statin therapy should be used in ACS, provided LDL is elevated.

\section{Plaque regression}

Whether regression of established coronary lesions can be achieved by any means is a key question. Earlier studies (10) relied on coronary angiography and assessed effects of various interventions including diets, exercise, surgical ileal shunt, as well as not so potent lipid-reducing drugs such as colestipol, colestiramine, niacin, and lovastatin. In the last decade, when imaging techniques for plaque evaluation were developed and more potent anti-lipidemic drugs became available, investigations of this issue regained impetus. Studies such as asteroid (11), reversal (12), meteor (13), and atheroma (14) investigations addressed this question, sharing the following characteristics: 1) analysis of plaque volume by intracoronary ultrasound and of carotid intima/thickness by ultrasound or magnetic resonance imaging; 2) use of potent statins including atorvastatin and rosuvastatin; 3) consistent and large LDL reductions, usually to 70-80 $\mathrm{mg} / \mathrm{dL}$ associated with significant increases in HDL; 4) follow-up of about 2 years with a sufficient number of patients who were carefully monitored; 5) randomization with appropriate controls and treatment groups. Figure 2 shows the results of the Meteor study.

In these circumstances, all investigators observed that major lipid lowering induced slower lesion progression or even plaque regression. The most significant finding seemed to be plaque stabilization in the treatment groups while lesion progression occurred uniformly among untreated controls. It is estimated that regression may occur in up to $20-25 \%$ of cases.

An alternative strategy to modify atherosclerotic evolution was tested by Nissen et al. (15), who administered recombinant ApoA-I Milano to CAD patients, avoiding atherosclerosis progression. Indeed, plaque volume as assessed by intracoronary ultrasound was reduced compared to controls. This strategy, however, is cumbersome, but the study's contribution must be taken as a proof of concept.

These impressive observations indicating that major lipid reductions by statins may indeed impact the nature of the atherosclerotic process, leading to plaque stabilization or even regression, have major significance for medical practice. The phenomenon of regression has been convincingly demonstrated for the first time in the history of atherosclerosis. These studies lend support to the notion that medical treatment is in fact extremely efficacious; indeed it is the only way by which the biochemical atherosclerotic process can be slowed. Whether it could be interrupted on a long-term basis, or even totally prevented, will depend on future investigations.

\section{How low is sufficient?}

The value of reducing LDL cholesterol levels substantially below $100 \mathrm{mg} / \mathrm{dL}$ in patients with CAD, particularly among those with stable disease, was demonstrated in the TNT Trial (7). In the TNT Trial, a total of 10,001 patients underwent randomization and received double-blind treatment with either 10 or $80 \mathrm{mg}$ atorvastatin. The relative risk reduction of the primary composite endpoint of death from $\mathrm{CAD}$, nonfatal non-procedure-related MI, resuscitation after cardiac arrest, and fatal or nonfatal stroke was $22 \%$ in the group given $80 \mathrm{mg}$ atorvastatin, compared to the group given $10 \mathrm{mg}$ of atorvastatin.

The TNT Trial provided evidence that the use of intensive therapy to reduce LDL cholesterol levels below $100 \mathrm{mg} /$ $\mathrm{dL}$ is associated with substantial clinical benefit in patients with stable CAD. Both atorvastatin groups had low rates of CAD events. The rate for the group given $10 \mathrm{mg}$ atorvastatin was lower than the rates reported with statin treatment in placebo-controlled, secondary prevention trials of populations with a baseline risk similar to that of TNT patients.

Cholesterol Treatment Trialists (7) also examined this question and their results showed an approximately linear relationship between the absolute reductions in LDL cholesterol and proportional reductions in the incidence of coronary and other major vascular events. This finding is reinforced by those of some direct randomized comparisons of different statin regimens, which also indicate that larger LDL cholesterol reductions produce larger reductions in vascular disease risk.

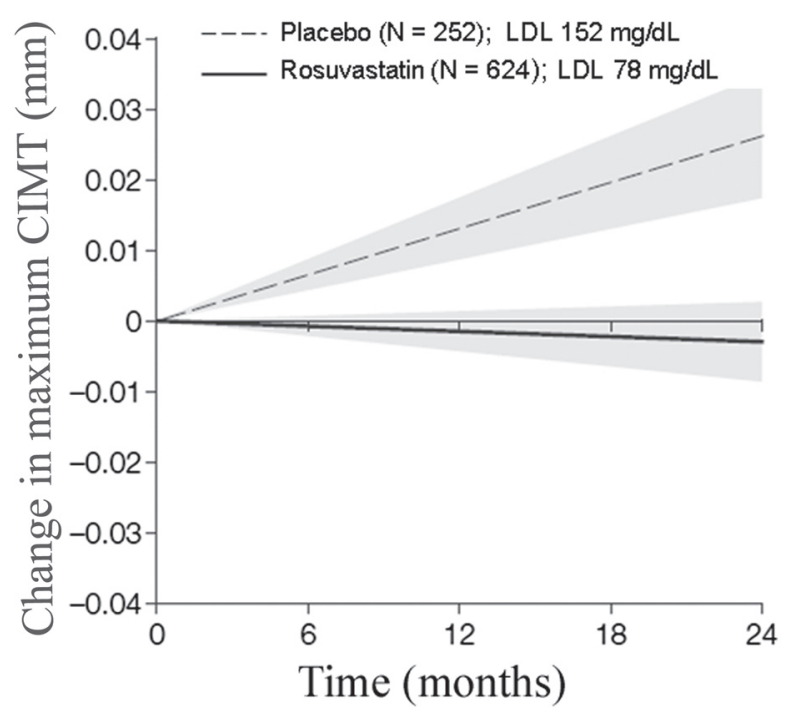

Figure 2. Evolution of carotid intima/media thickness (CIMT) during 24 months of treatment with rosuvastatin compared to placebo. Statin treatment stabilized carotid plaques. Reproduced with permission from Ref. 13. 
Reductions were similar irrespective of pretreatment cholesterol concentrations or other characteristics - age, gender, or pre-existing disease - of the study participants. A $1 \mathrm{mM}$ reduction in LDL cholesterol that is sustained for 5 years may well produce a proportional reduction in major vascular events of about $23 \%$.

A recent meta-analysis (16) involving 170,000 patients in 26 trials also demonstrated that lower LDL levels are indeed associated with greater reductions in CVD events. Furthermore, Forrester (17), analyzing experimental and clinical evidence, suggested that normal LDL values for humans are $\leq 70 \mathrm{mg} / \mathrm{dL}$. Current practice, therefore, holds that LDL should be lowered to about 70 or even less, at least for secondary prevention. For primary prevention most guidelines endorse $\leq 100 \mathrm{mg} / \mathrm{dL}$ as an acceptable value.

\section{Inflammation}

Since atherosclerosis is an inflammatory disease and elevated inflammatory markers such as high-sensitivity C-reactive protein (hsCRP) indicate a poor prognosis, a question has been raised regarding the possible value of reducing hsCRP in patients without overt hypercholesterolemia. Accordingly, Ridker et al. (18) in the Jupiter Trial, examined this issue in 17,802 men and women without known CAD, who had normal cholesterol levels but signs of systemic inflammation (high hsCRP) and they observed that rosuvastatin could cut in half the risk of heart attack or stroke.

Individuals with elevated hsCRP who are otherwise at a 5 to $10 \%$ or 10 to $20 \% 10$-year risk had substantive absolute risk reductions, suggesting that this group might well be considered candidates for statin therapy. They also demonstrated that men and women estimated to be at low risk (5\% 10-year risk estimates) had low absolute risk reductions and hence represent a group for which the absolute benefit of statin therapy is small. However, the issue of how important isolated high CRP is remains controversial and further studies are needed until a definitive answer is obtained.

\section{Long-term effects}

A concern about statin treatment is their long-term effects. Most clinical trials have only a duration of 4-5-years, which is too short an observational period, considering the life-long duration of atherosclerosis. A recent observation has shed some light on this question.

Long-term data obtained in the WOSCOPS over a period of 16 years (19) have been reported. Men prescribed statin therapy for 5 years during the clinical trial had fewer cardiovascular events a decade later, although a majority of the study cohort stopped taking their cholesterol-lowering medication. Over the post-trial period, when treatment was under the control of the patients and their physicians, a statistically significant reduction in death from CHD or nonfatal AMI remained among treated patients compared to placebo-treated individuals. The results, according to the authors, were presumably due to the stabilization of existing plaque and a slowing of the progression of CAD.

However, the problem concerning the long-term effects of statins remains largely unresolved and is especially pertinent to young patients who need long-lasting treatments.

\section{Low HDL}

Treatment of abnormally low HDL levels is more difficult but potentially very significant as the role of HDL as target for therapy is being increasingly recognized. High doses of oral niacin (2-3 g/day or more) may be effective. A trial conducted on post-infarction patients has demonstrated that an increase in HDL-C levels obtained with gemfibrozil (600 $\mathrm{mg}$ twice daily) in patients with relatively low LDL-C levels prolongs reinfarction-free survival (20). We (21) also gave niacin to patients with low HDL and measured endothelial function after three months. Although niacin did not increase total HDL during this short period, endothelial function was improved in every patient, suggesting that niacin improved HDL function.

The ApoA-I Milano Trial (15) involved 57 ACS patients in a randomized, placebo-controlled trial. Intravenous recombinant ApoA-I Milano/phospholipid complex produced a significant regression of coronary atherosclerosis as measured by intravascular ultrasound, presumably related to an increase in reverse cholesterol transport from atheromatous lesions to the serum with subsequent removal by the liver.

In summary, statin therapy has definitive beneficial effects both in terms of secondary and primary prevention: it reduces overall cardiovascular events, including cardiac death, fatal and nonfatal AMI, stroke and the need for revascularization. These benefits were shown in men and women alike and irrespective of hypertension, diabetes, smoking habits, and also in the elderly. No increase of cancer was documented. Therefore, statin is the most valuable drug for the treatment of atherosclerosis.

\section{Unresolved issues in statin therapy}

As shown in Figure 3, there are many unresolved issues regarding statins. For instance, residual risk (Figure 4) after successful treatment has been reported to be about $65 \%$ in most studies. This means that, although highly significant from a statistical point of view and biologically meaningful as well, total cardiovascular risk is far from eliminated. Ideally, a treatment should eradicate a disease as done, for instance, with antibiotics when pneumonia is successfully treated. Hence, there is considerable room for improvement in atherosclerosis treatment. Possibly, adequate measures to correct lifestyle behavior are indicated. Another major 
problem is the long-term use of statins in young individuals; neither long-term effects nor side-effects have been adequately assessed. Therefore, judicious evaluation of risks/benefits must exerted by physicians on individual cases. Similarly, the issue of costs is fundamental giving the prevalence of atherosclerosis in poor countries. Remaining unresolved issues are self-evident as shown in Figure 3.

\section{Other drugs}

Renin-angiotensin system blockade by angiotensin-converting enzyme (ACE) inhibitors or by an angiotensin II (Ang II) subtype 1 receptor antagonist has been expanded beyond patients with heart failure or left ventricular systolic dysfunction. Important observations come from randomized controlled studies like the Heart Outcomes Prevention Evaluation (HOPE) Trial (22). The HOPE
Trial demonstrated that the ACE inhibitor ramipril reduced fatal and nonfatal vascular events by $20-25 \%$ in patients at high risk, including diabetics with additional risk factors or patients with clinical coronary, cerebral, or peripheral arterial atherosclerotic disease. In another study of the anti-

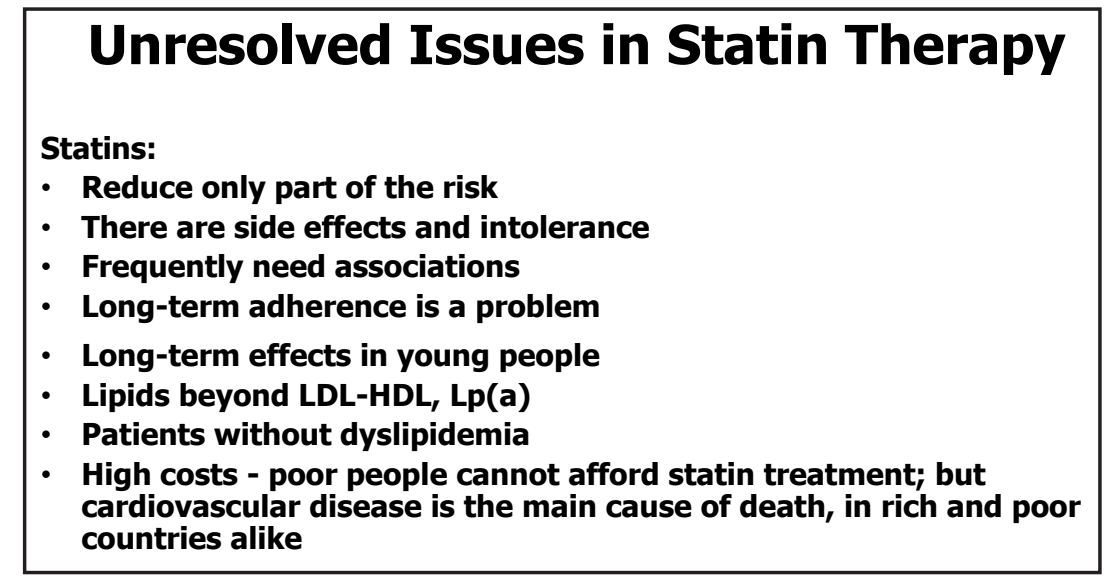

Figure 3. Potential problems regarding statins use. See text.

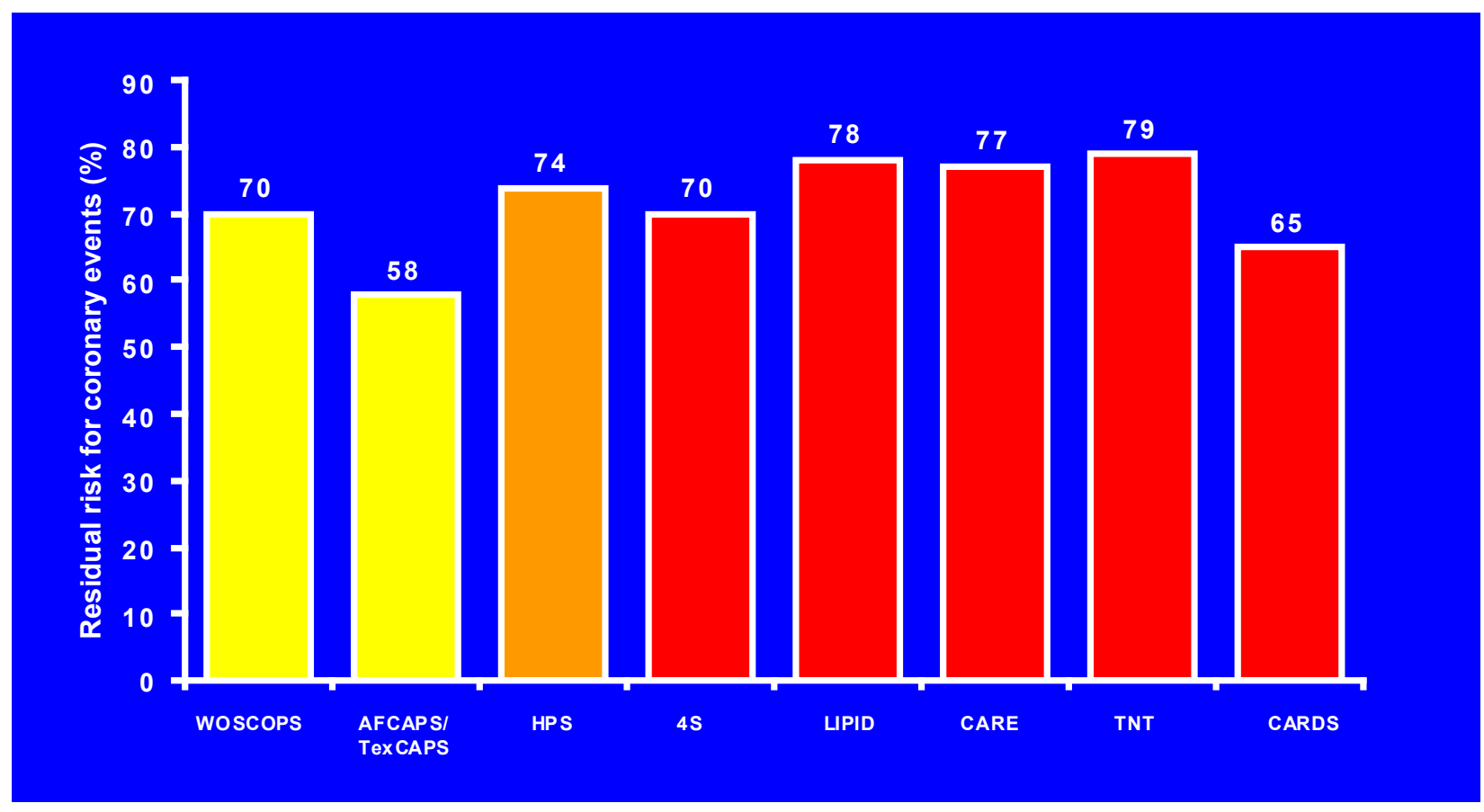

Figure 4. Residual risk in primary and secondary prevention studies. Note that the residual risk ranges from 58 to $79 \%$. WOSCOPS $=$ the West of Scotland Coronary Prevention Study (7). AFCAPS/TexCAPS = the Air Force/Texas Coronary Atherosclerosis Prevention Study (7); HPS = Heart Protection Study (7); 4S = Scandinavian Simvastatin Survival Study (7); CARDS = the Collaborative Atorvastatin Diabetes Study (7); LIPID = the Long-Term Intervention with Pravastatin in Ischemic Disease Study group (7); TNT = intensive lipid lowering with atorvastatin in patients with stable coronary disease; Treating to New Target Investigators (7); CARE = the effects of pravastatin on coronary events after myocardial infarction in patients with average cholesterol levels. Cholesterol and Recurrent Events Trial investigators (7). 
inflammatory effects of Ang II subtype 1 receptor blockade in hypertensive patients with microinflammation (EUTOPIA) (23), the Ang II subtype 1 receptor antagonist olmesartan significantly reduced vascular microinflammation in patients with essential hypertension. Patients with essential hypertension were a population at high risk similar to that in the HOPE Trial (22), with atherosclerotic disease and/or the key components of metabolic syndrome (e.g., type 2 diabetes mellitus and/or hyperlipidemia) in most cases. This was reflected by a rather high level of microinflammation and a mean baseline serum hsCRP concentration of $4.5 \mathrm{mg} / \mathrm{L}$ in both treatment groups. After 12 weeks of therapy with olmesartan, hsCRP was reduced by $20 \%$, whereas blood pressure reduction in the placebo treatment group had only a minor or no effect on inflammation markers. Thus, the beneficial cardiovascular effects documented for inhibitors of the renin-angiotensin system (e.g., ACE inhibitors and Ang II receptor antagonists) could be attributed, at least in part, to their anti-inflammatory action independent of the blood pressure-lowering effect.

Antiplatelet therapy is another very effective preventive measure. For instance, aspirin reduces the incidence of MI in males over the age of 50 years. Whether this approach should be employed in the general population or only in patients at high risk is unclear, and the optimal dosage is not known. A prudent approach would be to administer 81-325 $\mathrm{mg}$ daily to men with multiple coronary risk factors.

Fibrates can increase HDL and are especially effective in hypertriglycidemia. The Veterans Administration-High-Density Lipoprotein Intervention Trial (24) showed that fibrate treatment reduced the risk of a recurrent coronary event by $25 \%$ in patients with CAD, low HDL, modestly elevated TG, and normal LDL. Low HDL-C associated with elevated TGrich lipoproteins and their remnants represents an important therapeutic target. Obesity, metabolic syndrome, and type 2 diabetes are intimately associated with an atherogenic phenotype featuring low HDL-C combined with elevated TG-rich lipoproteins and small dense LDL. Hence, there is great interest in treatment strategies involving niacin, fibrates or their association to treat dyslipidemia. Niacin is especially potent in raising HDL and is more efficacious in raising HDL-C than fibrates; but niacin and fibrates comparably reduce TG-rich lipoproteins and LDL. Niacin is also effective in lowering lipoprotein levels.

\section{Healthy lifestyle}

An unhealthy lifestyle has devastating effects on survival, as shown by Peto et al. (25), who compared non-obese Americans to moderately and morbidly obese individuals, and smokers to non-smokers. The authors noticed that both conditions severely reduced life expectancy, reaching an incredible 10-year span among smokers. In the Whitehall Study (26), 19,019 male civil servants were followed for 38 years in London. A 10- to 15-year shorter life expec- tancy was observed among high-risk individuals, i.e., those with all three risk factors: smoking, hypertension and hypercholesterolemia. Similar reductions occurred with other risk factors such as diabetes. Unfortunately, most lay people as well as many doctors are not aware of these impressive figures!

Several studies have compared the effects of lifestyle interventions to those obtained with drug treatment in coronary disease. Ford et al. (27) reported on 10 such studies, as shown in Figure 5. It can be seen that interventions on risk factors were more effective in reducing mortality than all drugs and invasive procedures in the USA as well as in different European countries. Of particular note are the studies in Finland where a national and meticulous program was implemented (see ahead).

\section{Eating habits}

\section{Diets}

Countless studies on diets have been published (28) and the Mediterranean diet has been especially analyzed. The Mediterranean diet is characterized by low-saturated fat, high intake of vegetables, fruits and legumes plus olive oil and mild/moderate wine consumption. It is traditional in Mediterranean countries, especially Spain. Several studies were designed to test its efficacy. The PREDIMED Study (28) demonstrated the beneficial effects of a Mediterranean diet on risk factors, including inflammatory markers, glucose and blood pressure.

de Lorgeril et al. (29) carried out the Lyon Diet Heart Study in which 605 post-MI patients were randomly assigned to the prudent Western-type diet or to a Mediterranean diet during a mean follow-up of 46 months. The Mediterranean diet significantly reduced the combined endpoint of cardiac death, nonfatal AMI and noncardiac death.

The EPIC Trial (30) is an observational study of 22,043 adults who were followed for an average of 44 months in Greece. The effects of the Mediterranean diet on mortality were analyzed according to adherence to the diet using a well-defined score. Individuals who most adhered to the diet experienced a $25 \%$ reduction in general mortality, a $33 \%$ decrease in mortality due to CAD and a $24 \%$ decrease in cancer mortality. Trichopoulou et al. (31) estimated the contribution of each component of the Mediterranean diet in the EPIC Study regarding its overall effect on mortality and concluded that high intake of legumes/fruits and monounsaturated fats each contributed about $10 \%$; high intake of vegetables and low meat, $16 \%$, and moderate alcohol consumption about $23 \%$.

Sabaté et al. (32) studied the effects of nuts consumption on blood lipids in a pooled analysis of 25 trials in 7 countries. With a mean consumption of $67 \mathrm{~g} /$ day, nuts reduced cholesterol by $5.1 \%$, LDL by $7.4 \%$, and the LDL/HDL ratio by $8.3 \%$, while TG was reduced by $10.2 \%$ in individuals whose TG levels were at least $150 \mathrm{mg} / \mathrm{dL}$. The effects 


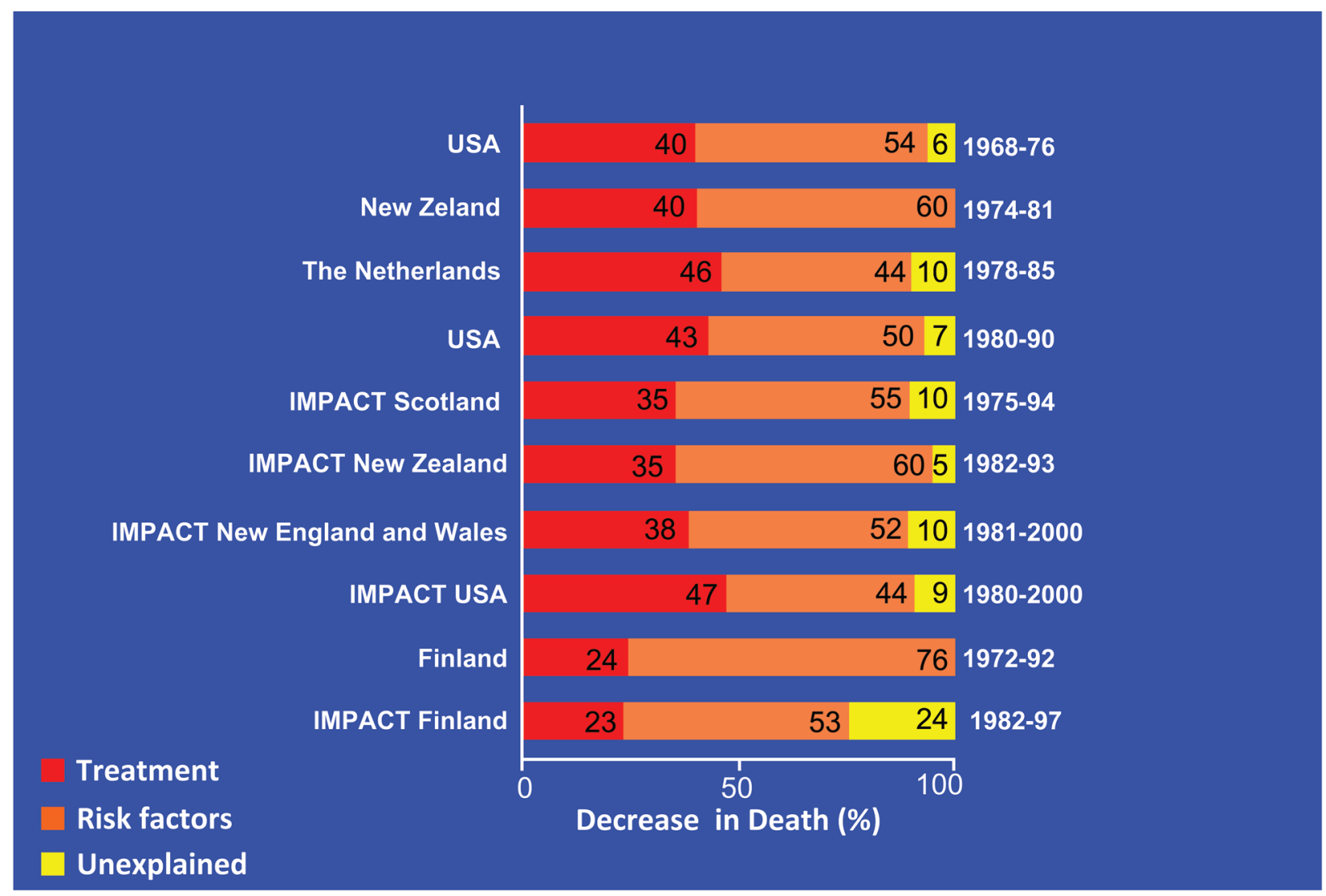

Figure 5. Comparison of treatments with drugs and interventions vs risk factor modifications. Note that overall lifestyle interventions are more efficient. Reproduced with permission from Ref. 27.

were dose related and different nuts had similar effects on blood lipids. Interestingly, effects were greatest in people with high baseline LDL and low body mass index (BMI) and among those on Western-type diets. Nuts are rich in plant protein (10-25\%) and unsaturated fatty acids (50-75\%) in addition to minerals, fiber and vitamins; therefore they are excellent nutritional complements.

As mentioned earlier, high-fat diets are notoriously detrimental. In North Karelia, Finland, a program was launched aimed at the adoption of a healthy diet and progressively extended to the entire country (33). From 1982 to 2007, total dietary fat was reduced to about $30 \%$, saturated fat was maintained at about $10 \%$, monounsaturated fat at 10 $15 \%$, and polyunsaturated fat at $5-10 \%$. As a consequence, coronary and total mortality declined by an amazing $85 \%$. Universities and several entities were involved in this program. Although Finland is a peculiar country because of its small size and highly educated citizens, this study is a proof of concept showing that major population lifestyle changes can be achieved.

High carbohydrate consumption is also a major source of calories and is presently recognized as a significant, if not the most important cause of inadequate diets world- wide. Effects of glucose overload have been meticulously investigated. O'Keefe et al. (34) studied the effects of a glucose-rich meal on plasma glucose, oxidative stress, endothelial function, and inflammation. They documented that variation in plasma glucose correlated directly with oxidative stress, increased CRP and decreased arterial endothelium dilation. But they also documented that the glucose increase could be substantially reduced by simultaneous ingestion of red wine, almonds, vinegar, and whey protein but was not affected by beer and gin, suggesting that this postprandial glucose increment is amenable to simple dietary interventions.

Regarding the efficiency of different types of diet, Sacks et al. (35) compared diets high and low in saturated fats, carbohydrates or proteins regarding their ability to induce weight loss in 811 overweight individuals followed for 2 years; they all reduced body weight comparably by about $4 \mathrm{~kg}$. The data indicate that reduction in caloric intake is the dominant factor regardless of how it is achieved.

Based on these findings, there is general consensus that the Mediterranean diet is indeed effective and possibly the most adequate for CVD prevention. Initiatives to correct unhealthy dietary habits, both at the individual and popula- 
tion levels, are generally frustrating. Initial gains in weight reductions for instance, are frequently overcome by weight regain over the next 1 to 2 years.

Salt is another fundamental component of the Western diet and is responsible in part for one major risk factor, i.e., hypertension which, on the other hand, is a major contributor to a devastating event, i.e., stroke. Even small increases in blood pressure cause a considerable increase in cardiovascular events in both women and men (36).

Tuomilehto et al. (37), in a study from Finland comparing higher and lower salt intake in $\mathbf{2 4 3 6}$ men and women, 25 to 64 years old, observed that higher salt intake increased coronary, cardiovascular and all deaths.

In the Intersalt Study, Perry and Beevers (38) observed that, in different countries, mortality due to stroke, is directly proportional to salt excretion in urine, which reflects salt ingestion.

Joossens and Kesteloot (39), in a single epidemiological investigation, observed that systolic blood pressure increased steadily as people aged among populations that added salt to their diet, such as Americans and Europeans; on the contrary, among primitive populations such as the Yanomani and Carajas Indians of Brazil, who did not add salt to their diets, blood pressure remained the same through ages 20 to 69 .

The impact of dietary salt reduction has been a constant preoccupation. Bibbins-Domingo et al. (40) calculated the impact of small reductions of salt intake on CVD over a one-year period. In this interesting simulation, the authors investigated the implications of a $3.0-\mathrm{g}$ reduction in salt ingestion in individuals aged 35 to 84 years regarding incidence of CAD, total MI, incidence of stroke, and total death among non-black men and women as well as in black men and women. There were significant reductions in all parameters and a huge saving in money expenditure.

Hence there is a plethora of evidence indicating that high-salt ingestion is deleterious and that even a small salt reduction such as 3-5 g/day has the potential to prevent cardiovascular events. In practice, a low-salt diet of $\leq 4.0$ $\mathrm{g} /$ day is usually recommended for hypertension. In heart failure patients, even smaller amounts may be needed.

\section{Trans-fatty acids}

Trans-fatty acids (TFA) ingestion has been associated with CAD (41). TFAs result from hydrogenation of fish and vegetable fats for industrial purpose, or else from natural digestion in ruminant animals. Usually they are measured in adipose tissue, whole blood or red blood cell membranes. Increased TFA ingestion has consistently been associated with worsening blood lipid profile, both LDL and HDL, in men and women as well, in a dose-dependent manner. They induce expression of inflammatory markers, increase insulin resistance and cause endothelial dysfunction (41). Hence, the metabolic milieu, which favors the development of atherosclerosis is induced and this is strong evidence of biological plausibility of an association between TFA intake and CVD.

On the other hand, the direct relationship between TFAs and CAD is less robust and has been deemed as "probable" in evidence-based guidelines (42). From our point of view, the evidence regarding lipids is unquestionable. Regarding $C A D$, the demonstration of a cause/effect relationship has been hampered by the long observational period needed to prove it in humans. However, as mentioned earlier, its biological plausibility is clear. Under these circumstances, we would favor the removal of TFAs from the food supply.

\section{Marine fatty acids}

About three decades ago, Bang et al. (43) reported that serum cholesterol and TG were lower in Greenland Inuits than in age-matched Danes, despite consumption of a diet very low in fruits, vegetables, and complex carbohydrates and high in fat and cholesterol. Kromann and Green (44) further reported that acute MI rates in this same population were markedly lower than those in Denmark. Sekikawa et al. (45) studied 281 Japanese born and living in Japan, 306 white Americans living in the USA, and 281 JapaneseAmerican men, i.e., Japanese men born and living in the USA, ages 40 to 49 years, regarding marine fatty acid consumption and atherosclerosis incidence. Japanese men had the lowest levels of atherosclerosis, whereas whites and Japanese Americans had similar levels. Japanese had 2-fold higher levels of serum marine-derived n-3 fatty acids than whites and Japanese Americans living in the USA.

Very high levels of marine-derived n-3 fatty acids have antiatherogenic properties that are independent of traditional cardiovascular risk factors and may contribute to reducing the burden of atherosclerosis in the Japanese, a lower burden that is unlikely to be the result of genetic factors.

Similar results were obtained in two recent studies in Japan (45). The Japan Eicosapentaenoic Acid Lipid Interventions Study (JELIS), a randomized trial of 18,645 Japanese subjects that examined the effectiveness of 1.8 $\mathrm{g}$ eicosapentaenoic acid per day plus a statin in reducing CHD rates, and the Japan Public Health Center-Based Study (JPHC), a 10-year prospective cohort study of 41,578 middle-aged Japanese subjects that examined dietary intake of marine-derived n-3 fatty acids; both concluded that marine-derived n-3 fatty acids have protective effects against nonfatal coronary events.

Once or twice weekly consumption of fish (i.e., $30 \mathrm{~g}$ fish per day) is associated with reduced risk of cardiac death in Western countries. Increasing fish intake above this level is of little additional benefit. In contrast, Japanese men consume more than $100 \mathrm{~g}$ fish every day on average from early in life. Interestingly, omega-3 intakes in Japan are only one quarter of those among Eskimos, the population that gave origin to the omega-3 hypothesis.

Intriguing observations have been recently made in Alaska (46). Although some investigators continue to report 
that Inuit consuming traditional diets have lower CHD rates, others are questioning this dogma. Recent evidence from the Genetics of Coronary Artery Disease in Alaska Natives (GOCADAN) Study indicates that carotid atherosclerosis is not only unrelated to omega-3 fatty acid intake but, surprisingly, its prevalence is now greater than that in US white populations. At least part of the problem in Alaska appears to be not a lack of omega-3 but the introduction of massive amounts of shortenings and other saturated fats into their Westernizing diet. Saturated and monounsaturated fat intakes reported in the GOCADAN were approximately 12 and $15 \%$ of energy, whereas in a similar age group in Japan, intakes were 8 and $9.4 \%$ of energy, respectively. This difference may be critical.

The Japanese experience, when contrasted to that of the Inuit and the Norwegians, suggests that the cardioprotective punch of the long-chain omega- 3 fatty acids may be no match for diets high in fat, particularly saturated fat.

In general, current recommendations include regular ingestion of fish, 2-3 times/week.

\section{Alcohol, red wine, polyphenols, resveratrol}

Several observational and experimental studies have suggested a beneficial effect of mild/moderate alcohol drinking on cardiovascular health and even total mortality (47). All clinical studies are concordant in that abstainers and heavy drinkers have higher mortality rates than individuals who drink moderately.

For instance, Mukamal et al. (48) reported on the drinking habits of 245,207 adult Americans from 9 representative samples of US adults, from 1987 to 2000 , as part of the annual National Health Interview Survey; over 10,000 cardiovascular deaths occurred during that period. An inverse and significant association was found between light/moderate drinking and CVD mortality when compared to abstainers but not between consumption above recommended limits and CVD mortality. The effect was present in men, women, whites and non-whites and included coronary and stroke mortality; however, risk reduction tended to be stronger for CHD than for cerebrovascular disease. Also, Ronksley et al. (49) reported the results of a recent meta-analysis based on 84 studies regarding the association between alcohol consumption and CVD; they observed a $25 \%$ risk reduction in CVD mortality among moderate drinkers compared to non-drinkers; coronary disease incidence and coronary artery disease mortality showed similar reductions.

Alcohol increases HDL, which is protective against atherosclerosis, and polyphenols in red wine have many protective effects including vasodilation, anti-oxidation and anti-platelet effects. Non-cardiovascular diseases have also been reported to be favorably influenced by moderate drinking. However, these clinical studies are observational and no controlled investigation has ever been performed; uncertainties also remain regarding drinking frequency, quantity, binge drinking, and sources of alcohol, i.e., whether from wine, beer, whisky, or others.

More recently, major interest has emerged regarding the possible beneficial effect of resveratrol - a polyphenol encountered in red wine, plants and fruits - on aging. So far the only intervention that effectively increases cell proliferation in culture and living organisms such as Saccharomyces cerevisae, fish and worms, is caloric restriction (50). Since resveratrol follows the same metabolic pathway as caloric restriction, including structural DNA preservation and P53 reduction, the hypothesis was raised that it could prolong life. Indeed, in experiments with hypercholesterolemic mice, Baur et al. (51) demonstrated that resveratrol did just that. However, in healthy mice we (da Luz PL, Tanaka LY, Brum PC, Krieger JK, Dourado PM, Favarato D, et al., unpublished data) did not detect life extension by either resveratrol or red wine. Nevertheless, we did find preservation of vascular function, increased aerobic capacity, P53 reduction, and telomere length preservation, all of which suggest protective actions of both red wine and small doses of resveratrol on vascular function.

Both these experimental and clinical observation studies show a potential benefit of moderate alcohol consumption, especially red wine. However, direct controlled studies on men are still locking.

\section{Exercise}

Regular exercise reduces cardiovascular events (52) through a number of physiological mechanisms. The most striking metabolic effect of exercise is to reduce plasma TG; but exercise also reduces insulin resistance and therefore contributes to diabetes control; regular exercise decreases blood pressure and increases HDL but has no effect on LDL. It improves mood, body weight, and inflammatory and hemostatic variables. Physical training improves exercise capacity, increases collaterals in CAD patients and improves endothelial function.

Following coronary artery bypass grafting (CABG) and percutaneous coronary intervention ( $\mathrm{PCl}$ ), it improves $\mathrm{VO}_{2}$ as well as quality of life. Hence, it is now considered to be part of recovery programs following these interventions. In the long term it reduces sudden coronary death; however, sudden death is more frequent during intense exercise than during moderate exercise. In our group, Casella-Filho et al. (53) assessed the effects of a 3-month supervised physical training program in 30 patients with metabolic syndrome including low HDL ( $\leq 40 \mathrm{mg} / \mathrm{dL}$ ) and noted that brachial arterial flow-mediated dilation improved significantly after exercise although total HDL and LDL remained at the same baseline values. Also, HDL from trained individuals significantly increased LDL resistance to oxidation. They interpreted the data as evidence that exercise can functionally improve HDL even if its total value does not change, probably by interference with its sub-fractions. Thus, even short periods of exercise can substantially ameliorate endothelial function while increasing resistance to LDL oxidation. 
The molecular mechanisms underlying the beneficial effects of exercise were examined by Werner et al. (54) in wild mice and in endothelial nitric oxide synthase (eNOS)and telomerase reverse transcriptase (TERT)-deficient mice subjected to 21 days of voluntary running. In normal mice, short-term voluntary running up-regulated cardiac telomerase activity, reduced the expression of proapoptotic mediators such as cell-cycle-checkpoint kinase 2, p16 and p53, compared to sedentary controls. Running also prevented doxorubicin-induced apoptotic cell death. In eNOS and TERT knockout mice, running had no effect, thus indicating the pivotal role of these enzymes as mediators of the effects of exercise. Further characterization permitted these investigators to establish that these salutary effects of running were also mediated by insulin growth factor- 1 . These effects persisted for at least 6 months. This is an important, novel contribution to our understanding of the mechanisms underlying the benefits of exercise.

These lines of evidence justify why cardiologists recommend regular exercise programs for CVD prevention and treatment. Tolerance to exercise through stress testing, however, should be assessed before entering such programs. Performing exercise within safe ranges of submaximum tolerance rather than at extenuating levels is a salutary practice, since excessive strain may induce sudden death in people with CAD. It is consensual among cardiologists that the optimal frequency of moderate exercise is $30 \mathrm{~min} /$ day, 4-5 times/week at least, on a long-term basis.

\section{Smoking}

A comparison of mortality by lung cancer in people who never smoked, those who quit smoking at age 30 or age 50 , and those who continued to smoke is very revealing (1). People who never smoked had almost no mortality by age 75 due to cancer; people who continued to smoke, had a death rate about 12 times higher; quitting at age 30 was better than at 50 , but in both cases it was significantly better than continuing to smoke.

In heart disease, many studies have shown the benefits of not smoking or quitting smoking. lestra et al. (55), reviewing studies on the effects of smoking cessation, estimated at $35 \%$ the reduction in mortality among patients with CAD and at $50 \%$ in the general population. This greater benefit in the general population is largely attributable to cancer prevention. Although quitting smoking has been a formal cardiologist recommendation for many years, its implementation remains a considerable challenge.

\section{Obesity and diabetes}

Obesity is one of the most prevalent risk factors, not only in Brazil but also all over the world. Even children and adolescents are suffering, which is a unique phenomenon in the history of humanity. A BMI above 30 is considered obesity while the normal index ranges from 23 to 25 . Causes of obesity are essentially two: 1) excessive caloric ingestion mainly through foods rich in fats and carbohydrates and 2) lack of exercise. Both situations are frequently associated with psychological factors including anxiety, stress and depression.

Obesity is frequently associated with diabetes and metabolic syndrome, which in turn predispose to CAD. As shown above (25), obesity reduces life expectancy and greatly impairs quality of life.

In principle, obesity can be avoided or treated. Several measures are required for this purpose: a diet with no excessive calories, principally restricting saturated fats and carbohydrates; regular exercise; medications to control excessive anger, and, most recently, bariatric surgery. But all require major changes in lifestyle. Cognitive behavioral therapy (56) is of particular value in this respect, as well as counseling by a nutritionist. Unfortunately, the long-term efficacy of weight reducing programs is disappointing, as shown by the Diabetes Prevention Program Research Group (57); although patients respond well initially, they regain weight over the next 1-2 years. Thus, we emphasize the need for patients to avoid gaining weight since programs to lose weight require considerable determination and personal "sacrifices" and hence are especially hard to implement on a long-term basis.

\section{Multiple interventions}

Some population studies are particularly relevant regarding human longevity (58). Japanese in Okinawa, Californians in Loma Linda and Italians in Sardinia are known for their exceptionally long survival rate and healthy behavior under normal environmental conditions. Independent of their origins, five traits are common to all these communities: they do not smoke, they prioritize the family, maintain constant physical activity, have an active social life, and eat fruits, vegetables and whole grains. Use of medications is virtually unheard of. In Brazil, Veranópolis, in Rio Grande do Sul, is also known for exceptional longevity (59). The life habits of its inhabitants are quite similar to those of the communities cited above; one common characteristic with the Sardinians is regular wine drinking. No genetic traits seem to explain these findings. These "nature's experiments" demonstrate how important a healthy lifestyle is for preservation of a long, active life. Figure 6 illustrate these common features.

Fraser and Shavlik (60) analyzed the effects of appropriate diet, non-smoking and exercise among Adventists in California compared to general Californian population; they observed a gain in life expectancy at 30 years, of 7.28 years in men and 4.42 in women who followed the recommended healthy habits.

Ornish et al. (61) published a remarkable study of people who were subjected to intensive lifestyle changes, including diet, exercise, social, religious, and psychological 


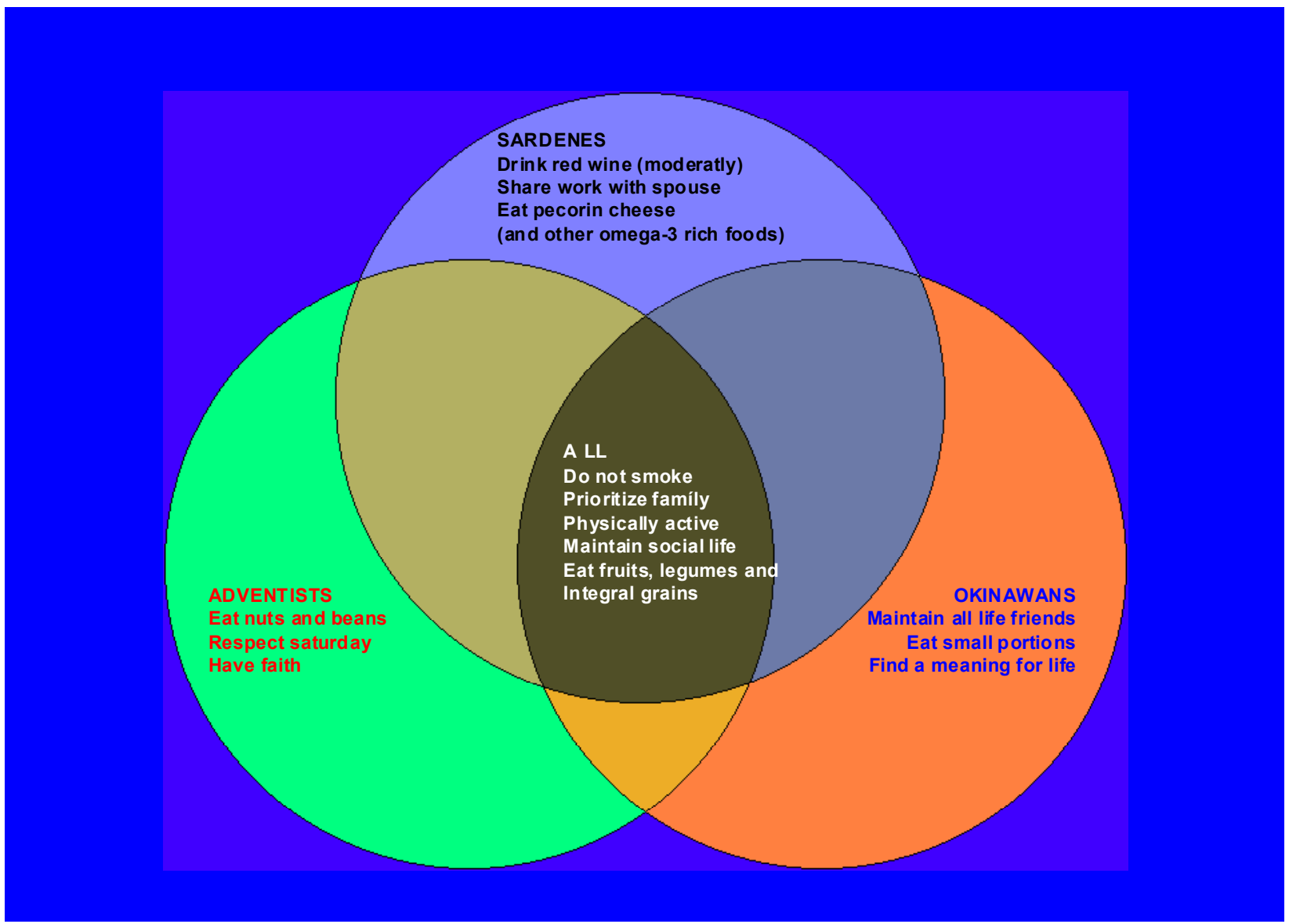

Figure 6. Common lifestyle features among populations who live longest. Reproduced with permission from Ref. 58.

counseling. Forty-eight patients were randomly assigned to the intensive regimen or to usual care, and subjected to coronary angiography for lesion quantification. After five years, lesion regression was observed in the treatment group, while progression occurred among controls. Admittedly, such intense regimen is difficult to apply to most people; nevertheless, the study does prove the point that a proper lifestyle can modify the natural history of atherosclerotic plaques.

Knoops et al. (62) reported on pooled results of the HALE, SENECA and FINE studies (Figure 7). The effects of diet, exercise, not smoking, and moderate alcohol consumption on event rate were analyzed in 1507 elderly men and 832 women followed for 12 years. A proper diet and moderate alcohol consumption both reduced risk by $25 \%$; regular exercise and not smoking, both reduced risk by $40 \%$; most impressive, individuals who observed all four habits, had a $65 \%$ risk reduction. It is noteworthy that this figure by far exceeds the best results obtained with drug therapy in all secondary prevention trials!

Taken together, these studies highlight the major impact of very simple measures on general health.

\section{Psychological and environmental factors}

Psychological, social and environmental factors have long been recognized as capable of influencing the development and clinical evolution of atherosclerosis. In-depth discussion of these many factors can be found elsewhere (56); here we only intend to illustrate how some of them have an impact on clinical settings. In addition, their importance derives from the fact that they are quite frequent and in many instances their clinical manifestations resemble organic diseases, such as palpitations and chest discomfort, thus leading to erroneous diagnoses. CAD has been related to five specific psychological factors (56): anxiety, depression, character traits and personality, social isolation, and chronic life stress. Work conditions, family (marital status, widowhood, parent/child relationships) and chronic illnesses are among the most common conditions in which chronic stress may occur. For instance, work stress, a form of chronic life stress, may affect CVD by two mechanisms: 


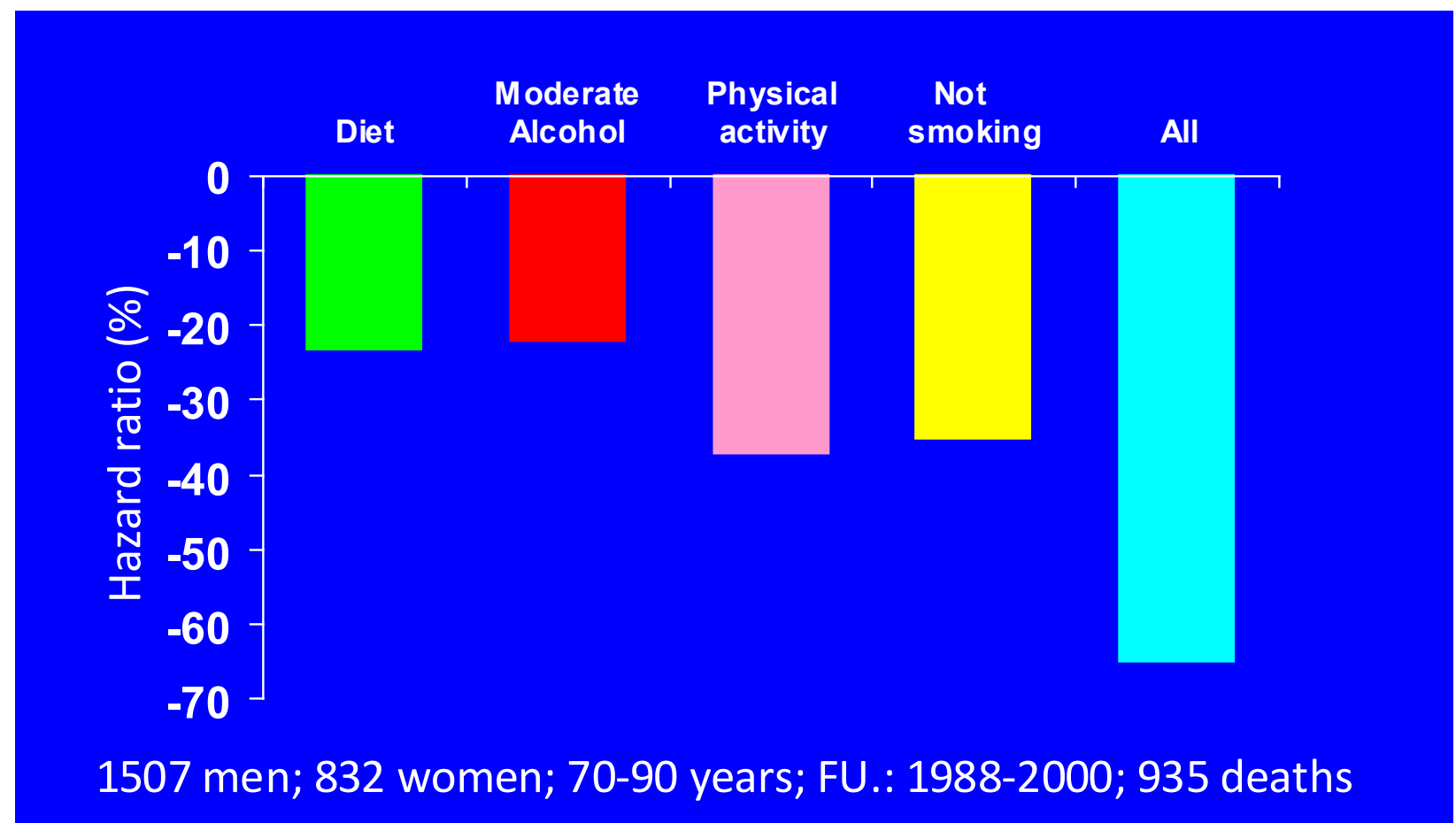

Figure 7. Comparison of four healthy habits among elderly people. Note that those who adopted all four healthy behaviors had a risk reduction of about $65 \%$, which is greater than that obtained with any drug therapy. Reproduced with permission from Ref. 62 .

direct stimulation of neuroendocrine responses to stressors or indirectly by unhealthy behaviors: diet, smoking, lack of exercise, and excessive drinking (Figure 8). The autonomic nervous system is a major axis of neuroendocrine stress responses and work stress leads to disregulation of the hypothalamic-pituitary-adrenal axis. Indeed, Chandola et al. (63) assessed the influence of work stress on behavioral and physiological indices regarding $\mathrm{CHD}$ incidence in 10,308 civil servants of the Whitehall II Study over a 12-year follow-up. They observed that work stress was associated with poor health behavior (eating less fruits and vegetables), less physical activity, metabolic syndrome, lower heart rate variability, and elevated morning cortisol, especially in younger participants (37-49 years). Greater reports of work stress were associated with higher risk of CVD, i.e., fatal events, $\mathrm{MI}$ and definite angina. The authors calculated that about $32 \%$ of the effect of work stress on CHD can be explained by health behaviors (especially low physical activity and a poor diet) and the metabolic syndrome. Importantly, in the INTERHEART Study (64) that analyzed about 24,767 patients with first AMI in 52 countries, noted that permanent stress at the work place was associated with more than a 2 -fold increase in the risk of AMI, compared to subjects who reported no such stress.

Hamer et al. (65) investigated the extent to which behavioral and traditional risk factors accounted for the association between psychological distress and cardiovas- cular events. In a prospective study of 6576 healthy adult men and women, psychological distress was measured by the General Health Questionnaire and the subjects were followed for 7.2 years. Outcome events were non-fatal AMI, bypass surgery, angioplasty, stroke, heart failure, and cardiac mortality. Alcohol intake, physical activity, cigarette smoking, hypertension, and CRP were independently associated with psychological distress. The risk of CVD increased in proportion to the presence of psychological distress in gender- and age-adjusted models. Behavioral factors accounted for approximately $60 \%$ of variance, while traditional risk factors (CRP, 5.5\%, and hypertension, 13\%) accounted for modest amounts. The authors concluded that "the association between psychological distress and CAD is largely explained by behavioral processes". Hence, health behavior change should be the main target for treatment when focusing on psychological distress. Lower occupational status and low job control have also been linked to $\mathrm{BMI}$ and central obesity, two known risk factors for CAD (66).

Strategies to deal with psychological stress include several interventions. Exercise, which is commonly recommended to prevent CAD, also has favorable effects on depression. The impact of psychosocial interventions added to cardiac rehabilitation programs was assessed by Linden et al. (67) in a meta-analysis of 23 randomized trials; during a 2-year follow-up, psychosocial intervention had a favorable 


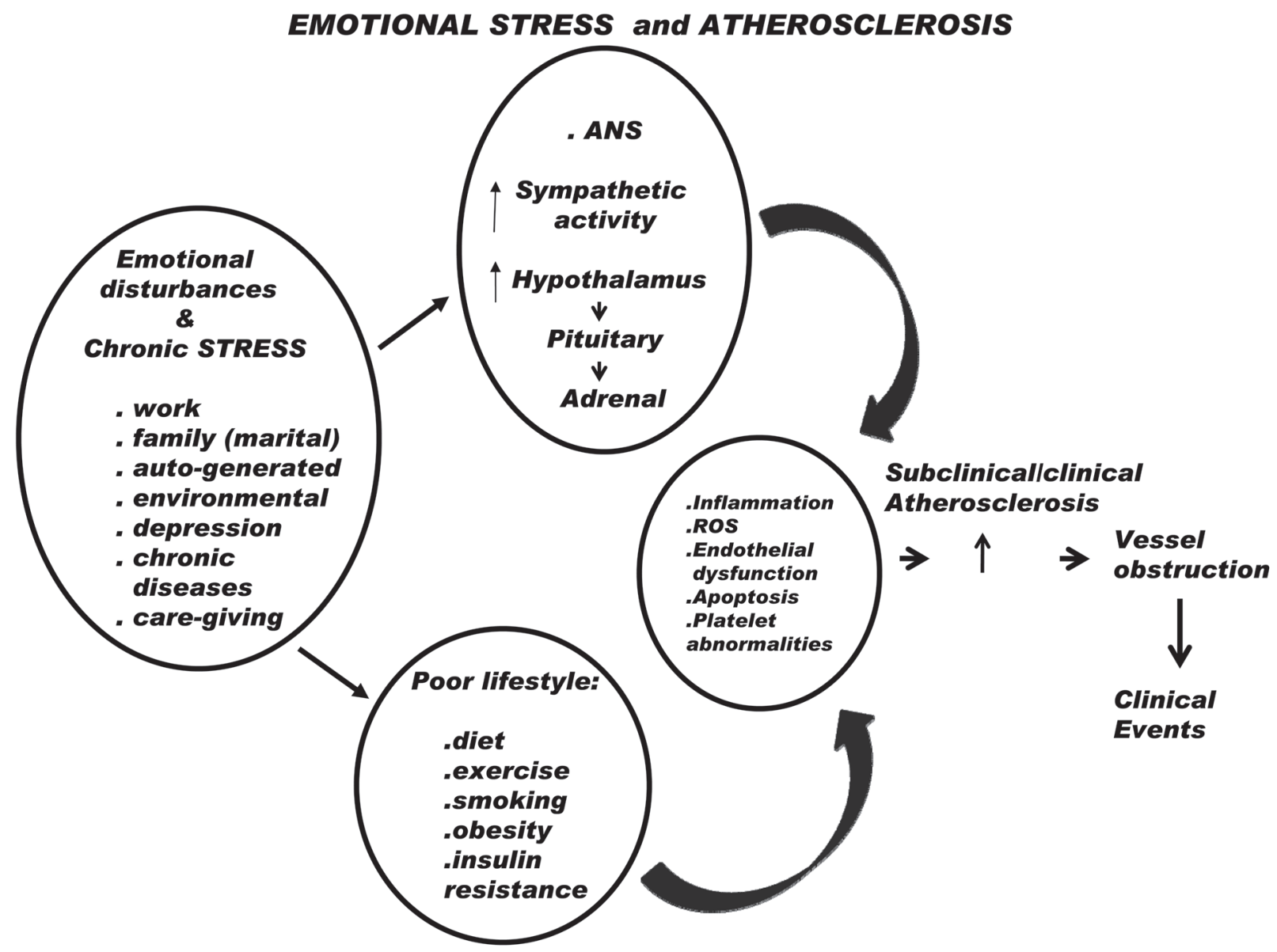

Figure 8. Schematic representation of the relationship between mental stress, atherosclerosis and clinical events. Chronic emotional stress may be induced by several life circumstances. They can cause hormonal activation on the one hand and, on the other, induce behaviors that lead to atherosclerosis development and progression. ANS = autonomic nervous system. ROS = reactive oxygen species.

impact on mortality and recurrent infarction. However, they (67) observed that such positive effect was dependent on the efficacy of the psychological intervention; thus, when stress was not reduced, the intervention had no effect. In fact, absence of a response seemed to identify a subgroup of individuals at particularly high risk. Other investigations suggested mixed results.

Psychopharmacologic therapies have also been advocated. The SADHART Trial (67) demonstrated that sertraline, which is an effective antidepressant drug, can be safely prescribed to treat depression in patients with known CAD; but the study was not powered to analyze events. On the other hand, tricyclic anti-depressants increased the risk of subsequent MI, as shown by Cohen et al. (68).

More recently, behavioral cognitive therapy has been incorporated into clinical practice as a valuable tool for patients with established coronary disease or multiple risk factors who need lifestyle changes for event and recurrence prevention, or better adherence to treatment. It should be viewed as adjunct therapeutic intervention; together with drug therapy it may increase the effectiveness of rehabilitation programs and long-term adherence to preventive measures.

As stated by Rozanski et al. (56), the "emerging field of behavioral cardiology" is a relatively new area of interest for research and practice. From the patients' perspectives some aspects need clarification: it is not uncommon that patients do not recognize or do not accept that psychological factors may produce a significant impact on their health; as a consequence they do not spontaneously mention them to their physicians; they may consider, for instance, that marital problems are intimate problems and should not be mentioned in a regular consultation. Furthermore, lay persons frequently consider that they can handle such 
problems on their own, when in fact professional counseling can be necessary. Finally, acceptance of psychological counseling is still hampered by all sorts of misconceptions. While requests by the attending physician of a second opinion from another specialist, let's say, a pneumologist, is readily accepted by the patient, the same request for a psychologist's opinion is questioned, ignored or flatly dismissed. From a doctor's perspective, more awareness of such problems is needed; and then, appropriate inquiries should be carried out to identify them. Without intruding into personal issues, that a patient might want to keep to himself, some general questions can be posed, such as: "Do you feel you are going through a particularly difficult time in your life?". The answer can offer a suggestion as to whether emotional stress is part of a given situation. Of course, in this scenario mutual confidence between doctor and patient is of paramount significance.

Since Freud's incursions into the unconscious, it became clear how fundamental it is to understand the human soul. Although the new technological era has unraveled so many biological phenomena, human behavior remains a Pandora's box. Behavioral cognitive therapy is a new tool that can help not only strictly psychological dysfunction, but also patients whose poor behavior leads to unhealthy habits and hence, to atherosclerosis.

\section{The five most important factors}

As shown above, several factors contribute to a healthy lifestyle. Based on the 16-year follow-up of the Health Professional Study, Chiuve et al. (69) identified five items associated with lower cardiac risk: non-smoking, BMI $\leq 25$, regular exercise (30 min/day), healthy diet (fruits, vegetables, low saturated fat) and 5-30 g alcohol/day. For each of the items followed there was a corresponding decrease in risk and this was true regardless of medication use, and was applicable to both men and women. Similarly, strokes were also significantly reduced among 43,685 men and 712,423 women who followed the same five recommendations (70). Note that these five factors are not particularly difficult to follow; however, experience shows that it is much easier to adhere to them in a preventive fashion rather than adopting them when atherosclerosis is already present and unhealthy behavior needs correction.

\section{Policies required}

Implementation of a healthy lifestyle is notoriously difficult, both at the individual and population levels. For individuals, the long-term dangerous consequences of a poor lifestyle should be clearly stated by doctors, especially because many risk factors are silent, and therefore the need for modifying habits may not be readily understood by patients. Secondly, global care is mandatory, including nutritional and psychological counseling. Regarding population-based programs, the contribution of different social components is fundamental. Namely, a) schools must be a focus because habits are better assimilated at an early age; b) government can influence society through regulatory policies; c) the media can help implement healthy lifestyles since its messages permeate all levels of societies and are extremely powerful; d) parents/family play an important role since habits acquired within the family are strongly respected; the family is the most important nucleus where behavior is acquired because it is based mainly on examples; e) medical societies have the obligation to transmit scientific knowledge to the society in simple, clear language. They must "translate" discoveries into practical lessons that will become actions.

Although difficult, this is a task that health professionals and society alike must tackle.

\section{Conclusions}

Drugs are powerful, indispensable weapons against CVD. However, because they are expensive, they have side effects and are only partially effective, they are not sufficient. The issue of costs is a major one since CVD hits poor countries as well as rich ones, and individual patients cannot cope with long treatment expenses. In addition, even rich countries are suffering with the escalating costs of medical care.

In contrast, a healthy lifestyle is inexpensive, safe and effective. However, it is not simple to implement. It requires changes in traditional habits, including diet, exercise and smoking. It also demands discipline because it interferes with some practices that are deemed pleasant. Furthermore, determination is needed since a healthy lifestyle is predicated upon long-term behavior. In addition to responsible medical care, psychological and nutritional counseling, social and family support are also needed to implement behavior modification. Experiences so far demonstrate how hard it is to obtain such changes; old habits are difficult to modify. Application to large communities is another obstacle, but a few experiences prove that it is possible. Admittedly, these population policies represent a major challenge for the medical community and society as well. However, in view of the predicted CVD epidemics ahead of us, this task will have to be faced.

\section{Acknowledgments}

Research supported by FAPESP (\#2009/51324-5) and Bradesco S.A., special grant. 


\section{References}

1. Jamison DT, Breman JG, Measham RA, Alleyne G, Claeson $M$, Evans DB, et al. Cost-effective strategies for noncommunicable diseases, risk factors, and behaviors. Priorities in Health World Bank 2006; 97-128.

2. SUS - Ministério da Saúde Brasil. Mortes por doenças cardiovasculares caem $20,5 \%$ no Brasil. http://portal.saude. gov.br/portal/aplicacoes/noticias/default.

3. da Luz PL, Bertini PJ, Favarato D. Noninvasive detection of coronary artery disease - challenges for prevention of disease and clinical events. Clinics 2005; 60: 415-428.

4. Keys A, Aravanis C, Blackburn HW, Van Buchem FS, Buzina $\mathrm{R}$, Djordjevic BD, et al. Epidemiological studies related to coronary heart disease: characteristics of men aged 40-59 in seven countries. Acta Med Scand Suppl 1966; 460: 1-392.

5. Kannel WB, Dawber TR, Kagan A, Revotskie N, Stokes J III. Factors of risk in the development of coronary heart disease - six year follow-up experience. The Framingham Study. Ann Intern Med 1961; 55: 33-50.

6. Friedman M, Friedland GW. As dez maiores descobertas da medicina. São Paulo: Ed. Companhia das Letras; 2000.

7. Cholesterol Treatment Trialists' (CTT) Collaborators. Efficacy and safety of cholesterol-lowering treatment: prospective meta-analysis of data from 90,056 participants in 14 randomized trials of statins. Lancet 2005; 366: 1267-1278.

8. Redberg RF, Benjamin EJ, Bittner V, Braun LT, Goff DC Jr, Havas S, et al. AHA/ACCF [corrected] 2009 performance measures for primary prevention of cardiovascular disease in adults: a report of the American College of Cardiology Foundation/American Heart Association task force on performance measures (writing committee to develop performance measures for primary prevention of cardiovascular disease): developed in collaboration with the American Academy of Family Physicians; American Association of Cardiovascular and Pulmonary Rehabilitation; and Preventive Cardiovascular Nurses Association: endorsed by the American College of Preventive Medicine, American College of Sports Medicine, and Society for Women's Health Research. Circulation 2009; 120: 1296-1336.

9. Cannon CP, Braunwald E, McCabe $\mathrm{CH}$, Rader DJ, Rouleau $\mathrm{JL}$, Belder R, et al. Intensive versus moderate lipid lowering with statins after acute coronary syndromes. N Engl J Med 2004; 350: 1495-1504.

10. da Luz PL, Solimene MC, Pileggi F. [Regression of human coronary atherosclerosis. Mechanisms and clinical implications]. Arq Bras Cardiol 1995; 64: 1-6.

11. Nissen SE, Nicholls SJ, Sipahi I, Libby P, Raichlen JS, Ballantyne $\mathrm{CM}$, et al. Effect of very high-intensity statin therapy on regression of coronary atherosclerosis: the ASTEROID trial. JAMA 2006; 295: 1556-1565.

12. Nissen SE, Tuzcu EM, Schoenhagen P, Crowe T, Sasiela WJ, Tsai J, et al. Statin therapy, LDL cholesterol, C-reactive protein, and coronary artery disease. N Engl J Med 2005; 352: $29-38$.

13. Crouse JR III, Raichlen JS, Riley WA, Evans GW, Palmer $\mathrm{MK}, \mathrm{O}$ 'Leary $\mathrm{DH}$, et al. Effect of rosuvastatin on progression of carotid intima-media thickness in low-risk individuals with subclinical atherosclerosis: the METEOR Trial. JAMA 2007; 297: 1344-1353.

14. Tang TY, Howarth SP, Miller SR, Graves MJ, Patterson AJ,
King-Im JM, et al. The ATHEROMA (Atorvastatin Therapy: Effects on Reduction of Macrophage Activity) Study. Evaluation using ultrasmall superparamagnetic iron oxideenhanced magnetic resonance imaging in carotid disease. J Am Coll Cardiol 2009; 53: 2039-2050.

15. Nissen SE, Tsunoda T, Tuzcu EM, Schoenhagen P, Cooper CJ, Yasin M, et al. Effect of recombinant ApoA-I Milano on coronary atherosclerosis in patients with acute coronary syndromes: a randomized controlled trial. JAMA 2003; 290: 2292-2300.

16. Baigent C, Blackwell L, Emberson J, Holland LE, Reith C, Bhala N, et al. Efficacy and safety of more intensive lowering of LDL cholesterol: a meta-analysis of data from 170,000 participants in 26 randomised trials. Lancet 2010; 376: 16701681.

17. Forrester JS. Redefining normal low-density lipoprotein cholesterol: a strategy to unseat coronary disease as the nation's leading killer. J Am Coll Cardiol 2010; 56: 630-636.

18. Ridker PM, Danielson E, Fonseca FA, Genest J, Gotto AM $\mathrm{Jr}$, Kastelein JJ, et al. Rosuvastatin to prevent vascular events in men and women with elevated C-reactive protein. N Engl J Med 2008; 359: 2195-2207.

19. Ford I, Murray H, Packard CJ, Shepherd J, Macfarlane PW, Cobbe SM. Long-term follow-up of the West of Scotland Coronary Prevention Study. N Engl J Med 2007; 357: 14771486.

20. Briel M, Ferreira-Gonzalez I, You JJ, Karanicolas PJ, Akl $\mathrm{EA}, \mathrm{Wu} \mathrm{P}$, et al. Association between change in high density lipoprotein cholesterol and cardiovascular disease morbidity and mortality: systematic review and meta-regression analysis. BMJ 2009; 338: b92.

21. Benjo AM, Maranhao RC, Coimbra SR, Andrade AC, Favarato $\mathrm{D}$, Molina MS, et al. Accumulation of chylomicron remnants and impaired vascular reactivity occur in subjects with isolated low HDL cholesterol: effects of niacin treatment. Atherosclerosis 2006; 187: 116-122.

22. Yusuf S, Sleight P, Pogue J, Bosch J, Davies R, Dagenais G. Effects of an angiotensin-converting-enzyme inhibitor, ramipril, on cardiovascular events in high-risk patients. The Heart Outcomes Prevention Evaluation Study Investigators. N Engl J Med 2000; 342: 145-153.

23. Fliser D, Buchholz K, Haller $\mathrm{H}$. Antiinflammatory effects of angiotensin II subtype 1 receptor blockade in hypertensive patients with microinflammation. Circulation 2004; 110: 1103-1107.

24. Rubins HB, Robins SJ, Collins D. The Veterans Affairs High-Density Lipoprotein Intervention Trial: baseline characteristics of normocholesterolemic men with coronary artery disease and low levels of high-density lipoprotein cholesterol. Veterans Affairs Cooperative Studies Program High-Density Lipoprotein Intervention Trial Study Group. Am J Cardiol 1996; 78: 572-575.

25. Peto R, Whitlock G, Jha P. Effects of obesity and smoking on U.S. life expectancy. N Engl J Med 2010; 362: 855-856.

26. Clarke R, Emberson J, Fletcher A, Breeze E, Marmot M, Shipley MJ. Life expectancy in relation to cardiovascular risk factors: 38 year follow-up of 19,000 men in the Whitehall study. BMJ 2009; 339: b3513.

27. Ford ES, Ajani UA, Croft JB, Critchley JA, Labarthe DR, 
Kottke TE, et al. Explaining the decrease in U.S. deaths from coronary disease, 1980-2000. N Engl J Med 2007; 356: 2388-2398.

28. Parikh $\mathrm{P}, \mathrm{McDaniel} \mathrm{MC}$, Ashen MD, Miller JI, Sorrentino $\mathrm{M}$, Chan V, et al. Diets and cardiovascular disease: an evidence-based assessment. J Am Coll Cardiol 2005; 45: 1379-1387.

29. de Lorgeril M, Salen P, Martin JL, Monjaud I, Delaye J, Mamelle N. Mediterranean diet, traditional risk factors, and the rate of cardiovascular complications after myocardial infarction: final report of the Lyon Diet Heart Study. Circulation 1999; 99: 779-785

30. Trichopoulou A, Costacou T, Bamia C, Trichopoulos D. Adherence to a Mediterranean diet and survival in a Greek population. N Engl J Med 2003; 348: 2599-2608.

31. Trichopoulou A, Bamia C, Trichopoulos D. Anatomy of health effects of Mediterranean diet: Greek EPIC prospective cohort study. BMJ 2009; 338: b2337.

32. Sabaté J, Oda K, Ros E. Nut consumption and blood lipid levels: a pooled analysis of 25 intervention trials. Arch Intern Med 2010; 170: 821-827.

33. Puska P. Fat and heart disease: yes we can make a change - the case of North Karelia (Finland). Ann Nutr Metab 2009; 54 (Suppl 1): 33-38.

34. O'Keefe JH, Gheewala NM, O'Keefe JO. Dietary strategies for improving post-prandial glucose, lipids, inflammation, and cardiovascular health. J Am Coll Cardiol 2008; 51: 249255.

35. Sacks FM, Bray GA, Carey VJ, Smith SR, Ryan DH, Anton $\mathrm{SD}$, et al. Comparison of weight-loss diets with different compositions of fat, protein, and carbohydrates. $N$ Engl J Med 2009; 360: 859-873.

36. Vasan RS, Larson MG, Leip EP, Evans JC, O'Donnell CJ, Kannel WB, et al. Impact of high-normal blood pressure on the risk of cardiovascular disease. N Engl J Med 2001; 345: 1291-1297.

37. Tuomilehto J, Jousilahti $P$, Rastenyte $D$, Moltchanov V, Tanskanen A, Pietinen $P$, et al. Urinary sodium excretion and cardiovascular mortality in Finland: a prospective study. Lancet 2001; 357: 848-851.

38. Perry IJ, Beevers DG. Salt intake and stroke: a possible direct effect. J Hum Hypertens 1992; 6: 23-25.

39. Joossens JV, Kesteloot $\mathrm{H}$. Trends in systolic blood pressure, 24-hour sodium excretion, and stroke mortality in the elderly in Belgium. Am J Med 1991; 90: 5S-11S.

40. Bibbins-Domingo K, Chertow GM, Coxson PG, Moran A, Lightwood JM, Pletcher MJ, et al. Projected effect of dietary salt reductions on future cardiovascular disease. $N$ Engl $J$ Med 2010; 362: 590-599.

41. Lopez-Garcia E, Schulze MB, Meigs JB, Manson JE, Rifai $\mathrm{N}$, Stampfer MJ, et al. Consumption of trans fatty acids is related to plasma biomarkers of inflammation and endothelial dysfunction. J Nutr 2005; 135: 562-566.

42. Booker CS, Mann JI. Trans fatty acids and cardiovascular health: translation of the evidence base. Nutr Metab Cardiovasc Dis 2008; 18: 448-456.

43. Bang HO, Dyerberg J, Nielsen AB. Plasma lipid and lipoprotein pattern in Greenlandic West-coast Eskimos. Lancet 1971; 1: 1143-1145.

44. Kromann N, Green A. Epidemiological studies in the Upernavik district, Greenland. Incidence of some chronic diseases 1950-1974. Acta Med Scand 1980; 208: 401-406.
45. Sekikawa A, Curb JD, Ueshima H, El-Saed A, Kadowaki $\mathrm{T}$, Abbott RD, et al. Marine-derived n-3 fatty acids and atherosclerosis in Japanese, Japanese-American, and white men: a cross-sectional study. J Am Coll Cardiol 2008; 52: 417-424.

46. Harris W. Omega-3 fatty acids: the "Japanese" factor? J Am Coll Cardiol 2008; 52: 425-427.

47. da Luz PL, Coimbra SR. Wine, alcohol and atherosclerosis: clinical evidence and mechanisms. Braz J Med Biol Res 2004; 37: 1275-1295.

48. Mukamal KJ, Chen CM, Rao SR, Breslow RA. Alcohol consumption and cardiovascular mortality among U.S. adults, 1987 to 2002. J Am Coll Cardiol 2010; 55: 1328-1335.

49. Ronksley PE, Brien SE, Turner BJ, Mukamal KJ, Ghali WA. Association of alcohol consumption with selected cardiovascular disease outcomes: a systematic review and metaanalysis. BMJ 2011; 342: d671.

50. Howitz KT, Bitterman KJ, Cohen HY, Lamming DW, Lavu S, Wood JG, et al. Small molecule activators of sirtuins extend Saccharomyces cerevisiae lifespan. Nature 2003; 425: 191196.

51. Baur JA, Pearson KJ, Price NL, Jamieson HA, Lerin C, Kalra $A$, et al. Resveratrol improves health and survival of mice on a high-calorie diet. Nature 2006; 444: 337-342.

52. Manson JE, Greenland P, LaCroix AZ, Stefanick ML, Mouton $\mathrm{CP}$, Oberman A, et al. Walking compared with vigorous exercise for the prevention of cardiovascular events in women. N Engl J Med 2002; 347: 716-725.

53. Casella-Filho A, Chagas AC, Maranhao RC, Trombetta IC, Cesena FH, Silva VM, et al. Effect of exercise training on plasma levels and functional properties of high-density lipoprotein cholesterol in the metabolic syndrome. Am J Cardiol 2011; 107: 1168-1172.

54. Werner C, Hanhoun M, Widmann T, Kazakov A, Semenov A, Poss $\mathrm{J}$, et al. Effects of physical exercise on myocardial telomere-regulating proteins, survival pathways, and apoptosis. J Am Coll Cardiol 2008; 52: 470-482.

55. lestra JA, Kromhout D, van der Schouw YT, Grobbee DE, Boshuizen HC, van Staveren WA. Effect size estimates of lifestyle and dietary changes on all-cause mortality in coronary artery disease patients: a systematic review. Circulation 2005; 112: 924-934.

56. Rozanski A, Blumenthal JA, Davidson KW, Saab PG, Kubzansky L. The epidemiology, pathophysiology, and management of psychosocial risk factors in cardiac practice: the emerging field of behavioral cardiology. J Am Coll Cardiol 2005; 45: 637-651.

57. Knowler WC, Fowler SE, Hamman RF, Christophi CA, Hoffman HJ, Brenneman AT, et al. 10-year follow-up of diabetes incidence and weight loss in the Diabetes Prevention Program Outcomes Study. Lancet 2009; 374: 1677-1686.

58. National Geographic Brasil. http://www.nationalgeographic. com.br_.

59. Werle MH, Moriguchi E, Fuchs SC, Bruscato NM, de Carli W, Fuchs FD. Risk factors for cardiovascular disease in the very elderly: results of a cohort study in a city in southern Brazil. Eur J Cardiovasc Prev Rehabil (published online February 2, 2011) 2011.

60. Fraser GE, Shavlik DJ. Ten years of life: Is it a matter of choice? Arch Intern Med 2001; 161: 1645-1652.

61. Ornish D, Scherwitz LW, Billings JH, Brown SE, Gould KL, Merritt TA, et al. Intensive lifestyle changes for reversal of 
coronary heart disease. JAMA 1998; 280: 2001-2007.

62. Knoops KT, de Groot LC, Kromhout D, Perrin AE, MoreirasVarela $\mathrm{O}$, Menotti $\mathrm{A}$, et al. Mediterranean diet, lifestyle factors, and 10-year mortality in elderly European men and women: the HALE project. JAMA 2004; 292: 1433-1439.

63. Chandola T, Britton A, Brunner E, Hemingway H, Malik M, Kumari $\mathrm{M}$, et al. Work stress and coronary heart disease: what are the mechanisms? Eur Heart J 2008; 29: 640-648.

64. Rosengren A, Hawken S, Ounpuu S, Sliwa K, Zubaid M, Almahmeed WA, et al. Association of psychosocial risk factors with risk of acute myocardial infarction in 11119 cases and 13648 controls from 52 countries (the INTERHEART Study): case-control study. Lancet 2004; 364: 953-962.

65. Hamer M, Molloy GJ, Stamatakis E. Psychological distress as a risk factor for cardiovascular events: pathophysiological and behavioral mechanisms. J Am Coll Cardiol 2008; 52 : 2156-2162.

66. Marmot MG, Smith GD, Stansfeld S, Patel C, North F, Head
$J$, et al. Health inequalities among British civil servants: the Whitehall II study. Lancet 1991; 337: 1387-1393.

67. Linden W, Stossel C, Maurice J. Psychosocial interventions for patients with coronary artery disease: a meta-analysis. Arch Intern Med 1996; 156: 745-752.

68. Cohen HW, Gibson G, Alderman MH. Excess risk of myocardial infarction in patients treated with antidepressant medications: association with use of tricyclic agents. Am J Med 2000; 108: 2-8.

69. Chiuve SE, McCullough ML, Sacks FM, Rimm EB. Healthy lifestyle factors in the primary prevention of coronary heart disease among men: benefits among users and nonusers of lipid-lowering and antihypertensive medications. Circulation 2006; 114: 160-167.

70. Chiuve SE, Rexrode KM, Spiegelman D, Logroscino G, Manson JE, Rimm EB. Primary prevention of stroke by healthy lifestyle. Circulation 2008; 118: 947-954. 